\title{
Base Nacional Comum Curricular e Educação Infantil: a ciranda das Artes na Escola de Aplicação da UFPA
}

\section{Oíta de Cássia Cabral ORodrigues de Jrança*}

ORaquel Amorim dos fantos**

\section{RESUMO}

O presente estudo tem como tema a Base Nacional Comum Curricular e a Arte na Educação Infantil. Dessa forma, problematiza o conceito de criança na perspectiva da BNCC e a importância do brincar e interagir para o desenvolvimento artístico da criança na Educação Infantil. A pesquisa ocorreu no decorrer do primeiro semestre de 2018 na Escola de Aplicação da Universidade Federal do Pará. A abordagem da pesquisa é qualitativa, estruturada na bibliografia especializada no diálogo em arte, com a concepção de interação social; em se tratando do brincar tomamos como referências significativas produções da área, a metodologia adotou a pesquisa de campo, como instrumento de coleta de dados e a observação. Os resultados mostram por meio deste estudo que a BNCC desvela um conceito de criança histórico-

\footnotetext{
* Mestra em Educação pela Universidade Federal do Pará. Professora de Artes Visuais da Escola de Aplicação da Universidade Federal do Pará Membro do Núcleo de Estudos e Pesquisa sobre Formação de Professores e Relações Étnico-Raciais GERA/IFCH/UFPA.

** Doutora em Educação pela Universidade Federal do Pará. Professora da Universidade Federal do Pará/Campus de Bragança. Membro do Núcleo de Estudos e Pesquisa sobre Formação de Professores e Relações Étnico-Raciais GERA/IFCH/UFPA.
} 
social; a Escola de Aplicação promove a brincadeira e interação direcionando também para o fazer artístico, contribuem para o desenvolvimento das habilidades artísticas da criança, bem como para aprendizagens, desenvolvimento e socialização da criança no meio social.

Palavras-chave: BNCC. Educação Infantil. Brincar. Interagir.

\section{ABSTRACT}

The present study has as its theme the National Common Curricular Base and the Art in Early Childhood Education. In this way, it problematizes the concept of a child from the perspective of the BNCC and the importance of playing and interacting for the artistic development of the child in Early Childhood Education. The research was conducted during the first semester of 2018 at the School of Application of the Federal University of Pará. The research approach is qualitative, structured in the specialized bibliography in the dialogue in art, with the conception of social interaction; in the case of play we take as significant references productions of the area, the methodology adopted the field research, as instrument of data collection and observation. The results show by means of this study that the BNCC reveals a concept of historical-social child; the School of Application promotes the play and interaction, also directing the artistic work, contribute to the development of the child's artistic abilities, as well as

Key words: BNCC. Child education. Play. Interact

\section{INTRODUÇÃO}

A obra de Pieter Brueghel "Jogos Infantis" nos instiga a refletir como era ser criança no Renascimento. Nesta obra, o pintor retrata não menos do que oitenta e quatro brincadeiras infantis presentes na época em que viveu no

@rquivo Brasileiro de Educação, Belo Horizonte, v. 6, n. 14, mai-ago, 2018. 
século XVI, algumas já esquecidas ou reconfiguradas com o tempo e o lugar, sendo realizadas por adultos e crianças, pintadas como mini adultos; mostrando a alegria na interação entre as crianças promovida pelo brincar. Tal imagem visualmente só contribui para reforçar o que ela expressa que "o brincar" sempre teve importância para o desenvolvimento social da criança.

Mas não havia pelo adulto a preocupação ou o sentimento de cuidar da criança naquela civilização, época em que não existia ainda um conceito de infância. Nessa época, as pessoas não sabiam medir o tempo, desconheciam a data de nascimento e as fases que separam a nossa vida em infância, adolescência, vida adulta não diziam respeito às pessoas comuns. Segundo Ariès (1981) a construção do sentimento de amor pelas crianças e a preocupação com elas foi, durante muitos séculos, despercebido, ignorado, chegando mesmo a não existir. Sua tese indica o surgimento da noção de infância apenas no século XVII. Período de um contexto de descobertas e com grandes transformações que começam a se processar na transição para a emergente sociedade moderna.

Levou um tempo considerável nesse processo de desenvolvimento da sociedade até a criança ser considerada um ser de direito e requer cuidados. No Brasil, a Educação infantill embora reconhecida como direito de todas as crianças e dever do Estado, passa a ser obrigatório para as crianças de 4 e 5 anos apenas com a Emenda Constitucional no 59/20092, que determina a obrigatoriedade da Educação Básica dos 4 aos 17 anos. Essa extensão da obrigatoriedade foi incluída na Lei $n^{\circ}$ 9.394/1996, de Diretrizes e Bases da Educação Nacional em 2013, passando a obrigatoriedade de matrícula de todas as crianças de 4 e 5 anos em

\footnotetext{
${ }^{1}$ Com a Constituição Federal de 1988, o atendimento em creche e pré-escola às crianças de zero a 6 anos de idade torna-se dever do Estado. Posteriormente, com a promulgação da LDB, em 1996, a Educação Infantil passa a ser parte integrante da Educação Básica, situando-se no mesmo patamar que o Ensino Fundamental e o Ensino Médio. E a partir da modificação introduzida na LDB em 2006, que antecipou o acesso ao Ensino Fundamental para os 6 anos de idade, a Educação Infantil passa a atender a faixa etária de zero a 5 anos.

${ }^{2}$ BRASIL (2009).
}

@rquivo Brasileiro de Educação, Belo Horizonte, v. 6, n. 14, mai-ago, 2018. 
instituições de Educação Infantil.

Na primeira etapa da Educação Básica, e de acordo com os eixos estruturantes da Educação Infantil (interações e brincadeiras), devem ser assegurados seis direitos de aprendizagem e desenvolvimento, para que as crianças tenham condições de aprender e se desenvolver: Conviver, Brincar, Participar, Explorar, Expressar e Conhecer-se (BRASIL, 2017, p. 23). A criança vivenciando esses direitos citados na Escola de Aplicação poderá se desenvolver de várias formas inclusive artisticamente por meio da brincadeira. Vale lembrar sobre o ensino de arte que "À medida que a reforma curricular se consolida, as artes conquistam seu lugar nas escolas" (BARBOSA, 2011, p. 81).

Como primeira etapa da Educação Básica, a Educação Infantil é o início e o fundamento do processo educacional. As Diretrizes Curriculares Nacionais da Educação Infantil (DCNEl, Resolução CNE/CEB n 5/2009), em seu Artigo $4^{\circ}$, definem a criança como "sujeito histórico e de direitos, que interage, brinca, imagina, fantasia, deseja, aprende, observa, experimenta, narra, questiona e constrói sentidos sobre a natureza e a sociedade, produzindo cultura" (BRASIL, 2009, p. 3, Grifo nosso).

Na perspectiva da BNCC, a "interação durante o brincar caracteriza o cotidiano da infância, trazendo consigo muitas aprendizagens e potenciais para o desenvolvimento integral das crianças" (BRASIL, 2017, p. 33). Ao observar as interações e brincadeiras entre as crianças, é possível identificar, no decorrer das práticas pedagógicas, a expressão artística, dos afetos, a solidariedade, a resolução de conflitos, entre outras como afirma Vygotsky. "As interações da criança com as pessoas de seu ambiente desenvolvemIhe, pois, a fala interior, o pensamento reflexivo e o comportamento voluntário" (VYGOTSKY, 1984, p. 101).

Assim, o presente estudo, tem como tema a Base Nacional Comum Curricular (BNCC), arte e a Educação Infantil. Dessa forma, problematiza o 
conceito de criança na perspectiva da BNCC e a importância do brincar e interagir para o desenvolvimento artístico na Educação Infantil na Escola de Aplicação da Universidade Federal do Para (UFPA) a partir dos cinco campos de experiência, em relevância para este estudo, nos apropriaremos do campo: Traços, sons, cores e formas. Para dar conta de tal estudo emerge a seguinte questão problematizadora: Qual é o conceito de infância na perspectiva da BNCC e a importância do brincar e interagir para o desenvolvimento artístico da criança na Educação Infantil na Escola de Aplicação da UFPA?

Tem como objetivo geral investigar o conceito de infância proposto pela BNCC e a importância do brincar e interagir para o desenvolvimento artístico da criança na Educação Infantil na Escola de Aplicação, já que observamos por meio da leitura imagética da obra de Pieter Brueghel "Jogos Infantis" do século XVI que a maioria das brincadeiras retratadas na pintura atravessaram séculos e se fazem presente hoje, no brincar das crianças como uma grande ciranda na Escola de Aplicação.

E, O termo ciranda, empregado neste estudo, caracteriza-se pela formação de uma grande roda girando ao redor das diversas linguagens artísticas como: as Artes Visuais, a Música, o Teatro e a Dança, geralmente expressadas nas áreas da escola nos horários do recreio onde as crianças dançam ao som de ritmo lento ou acelerado e repetido das cantigas de roda, se dão justo na relação entre as crianças e às vezes com a inserção dos adultos que também se sentem chamados pela cantiga de roda também chamada de ciranda.

\section{O CAMINHO METODOLÓGICO...}

Para desvelar os resultados desse estudo, adotou-se como método a priori a pesquisa bibliográfica por meio do levantamento, da seleção e da

@rquivo Brasileiro de Educação, Belo Horizonte, v. 6, n. 14, mai-ago, 2018. 
análise do material já publicado a respeito do objeto estudado Lakatos e Marconi (2006), nos favorece uma excelente oportunidade ao pesquisador de refletir e organizar as informações publicadas em relação ao tema para, assim, construir seus conhecimentos.

A pesquisa ocorreu no decorrer do primeiro semestre de 2018. O estudo metodologicamente é de cunho qualitativo com a literatura especializada com Vygotsky (1984) sobre a concepção de interação social; Em se tratando da arte com Barbosa (2011) e Buoro (2009); brincar tem-se como referências a Kishimoto (2002) e Andrade (2012) e os documentos Diretrizes Curriculares Nacionais da Educação Infantil (BRASIL, 2009) e a Base Nacional Comum Curricular (BRASIL, 2017).

A metodologia adotada é uma pesquisa descritiva de acordo com Cervo, Bervian e Silva (2007). Para a aquisição dos resultados pretendidos, este estudo desenvolveu-se em duas etapas: a primeira fase ao levantamento da bibliografia sobre o objeto de pesquisa. Na segunda fase aplicou-se a observação, que em pesquisa educacional, parte de fatos constatados nas ciências do homem, referindo-se a comportamentos, nessa pesquisa o sujeito observado é a criança.

Para Vianna (2003, p. 12), corrobora afirmando:

A observação é uma das mais importantes fontes de informações em pesquisas qualitativas em educação. Sem acurada observação, não há ciência. Anotações cuidadosas e detalhadas vão constituir os dados brutos das observações, cuja qualidade vai depender, em grande parte, da maior ou menor habilidade do observador $e$ também da sua capacidade de observar, sendo ambas as características desenvolvidas, predominantemente, por intermédio de intensa formação. (VIANNA, 2003, p. 12).

O lócus da pesquisa escolhido foi a Escola de Aplicação3 da

\footnotetext{
${ }^{3}$ Fundada em 7 de março de 1963 como a escola primária da UFPA, pelo então reitor da instituição, José Rodrigues da Silveira Neto. Em 1964 foi criado o colégio universitário com o objetivo de atender os alunos que alcançavam o nível médio - à época conhecido como Ginásio de Aplicação. Em 1975, a escola primária e
}

@rquivo Brasileiro de Educação, Belo Horizonte, v. 6, n. 14, mai-ago, 2018. 
Universidade Federal do Pará, justificamos a escolha por se tratar de três motivos: primeiro, por ser uma instituição que oferece no seu corpo docente, profissionais especializados em diferentes linguagens artísticas: Artes Visuais, Música, Teatro e Dança, sendo ofertadas às crianças; segundo, essa instituição oferece uma área de lazer específica para a Educação Infantil, área essa que oportuniza diversas modalidades de brincadeiras às crianças, sem ter que disputar com os alunos de outros níveis de ensino o espaço; e, terceiro, uma das autoras ser professora de Artes Visuais desta instituição e ter um lastro pedagógico de quinze anos na Educação Infantil.

\section{Imagem 1- Frente da Escola de Aplicação da Universidade Federal do Pará}

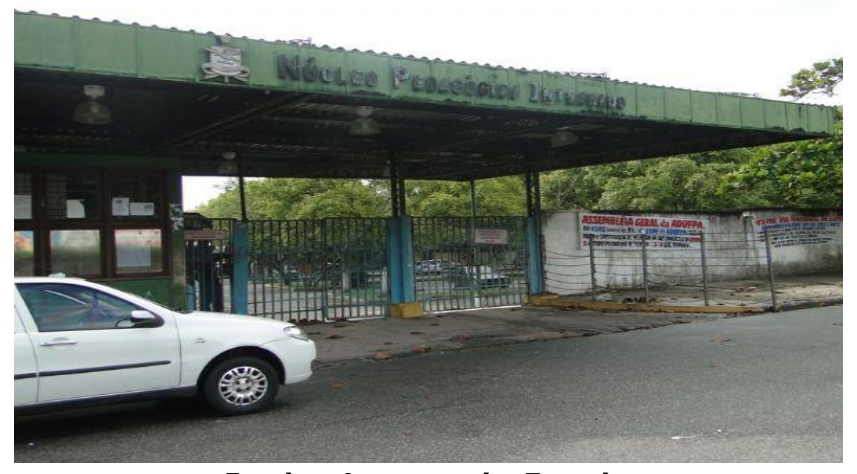

Fonte: Acervo da Escola

A Escola de Aplicação ofertando essa ciranda de artes aos alunos possibilita a nosso ver e referendado por Buoro (2009, p. 33) "Além do desenvolvimento da imaginação criadora e da percepção, destaca-se como questão de importante reflexão a possibilidade de o professor contribuir afetiva e cognitivamente para o desenvolvimento da expressão da criança.". Essa expressão artística se dá nas diversas linguagens, inclusive na escrita.

o centro universitário foram unificados, originando, assim, o Núcleo Pedagógico Integrado, acrescentado como um local de estágio para os alunos e bolsistas de licenciatura da UFPA. Desde 2006, o NPI passou a ser Escola de Aplicação, unidade acadêmica especial com estrutura administrativa própria que desenvolve educação básica, configurando-se como campo de estágio voltado para a experimentação pedagógica. Fonte:. Acesso em: 29 out. 2017.

@rquivo Brasileiro de Educação, Belo Horizonte, v. 6, n. 14, mai-ago, 2018. 
A título de percurso metodológico, nos interessou delimitar a coleta de dados por meio da observação na prática pedagógica das professoras da Escola de Aplicação em duas dimensões diferentes, quais sejam: primeiro, nos recreios das crianças, devido a esse momento ser compartilhado com as professoras e estagiários; e segundo, em evento ocorrido em maio de 2018 chamado: "Encontro da família na escola", esse por haver apresentações e exposições artísticas das crianças.

Portanto, na estrutura deste estudo, apresentamos as seguintes seções: Base Nacional Comum Curricular e o conceito de infância; Ciranda da arte na Educação Infantil na Escola de Aplicação da UFPA; O observado e desvelado na Escola de Aplicação e as considerações finais.

\title{
3 BASE NACIONAL COMUM CURRICULAR E O CONCEITO DE INFÂNCIA
}

\begin{abstract}
As creches e pré-escolas, ao acolher as vivências e os conhecimentos construídos pelas crianças no ambiente da família e no contexto de sua comunidade, e articulá-los em suas propostas pedagógicas, têm o objetivo de ampliar o universo de experiências, conhecimentos e habilidades dessas crianças, diversificando e consolidando novas aprendizagens, atuando de maneira complementar à educação familiar - especialmente quando se trata da educação dos bebês e crianças bem pequenas, que envolve aprendizagens muito próximas aos dois contextos (familiar e escolar), como a socialização, a autonomia e a comunicação (BRASIL, 2017, p. 32).
\end{abstract}

O fragmento citado na abertura desse subtítulo lembra ao professor que a criança não é uma tábula rasa4, logo, precisamos valorizar a bagagem de conhecimentos e vivências das crianças adquiridas no extraescolar. Bem como, é preciso desvelar o conceito de infância no escopo da BNCC, para entendermos a importância do interagir e o brincar

\footnotetext{
${ }^{4}$ Sobre os saberes inatos, Locke nega a ideia desses conhecimentos intrínsecos, pressupondo que ao nascer as pessoas não possuem nenhum tipo de conhecimento, mas são adquiridos desde a mais tenra idade, como argumenta em sua teoria da tábula rasa. Desse conceito empirista que nega a existência de ideias inatas surge a formulação de outro conceito, no qual a mente humana é comparada a uma tabula rasa, ou seja, ela representa um papel em branco pronto para ser preenchido pelo professor.
}

@rquivo Brasileiro de Educação, Belo Horizonte, v. 6, n. 14, mai-ago, 2018. 
para a criança que faz parte da infância contemporânea.

Tal documento se ampara nas Diretrizes Curriculares Nacionais para a Educação Infantil(DCNEI) (BRASIL, 2009), e esse último, por sua vez, anuncia o conceito de criança que devemos considerar no Art. $4^{\circ}$ As propostas pedagógicas da Educação Infantil deverão considerar que a criança, centro do planejamento curricular, é sujeito histórico e de direitos que, nas interações, relações e práticas cotidianas que vivencia, constrói sua identidade pessoal e coletiva, brinca, imagina, fantasia, deseja, aprende, observa, cria, expressa, estesia, experimenta, narra, questiona e constrói sentidos sobre a natureza e a sociedade, produzindo cultura.

Nessa perspectiva, Souza (2007), corrobora na construção do conceito de infância explanando:

\begin{abstract}
A concepção de criança, posta pelo Enfoque Histórico-Cultural, se sustenta na tese de que a criança só se desenvolve, isto é, se humaniza, mediante a apropriação da cultura e no processo de sua atividade. Todas as habilidades e aptidões humanas são, nesse sentido, formadas nas relações concretas - compreendidas na materialidade e imaterialidade - entre o homem e o mundo da cultura, tornando-se produtos e produtoras da história humana. Portanto, a criança, nessa perspectiva, não nasce com caráter humanizado, mas se humaniza pelos seus processos de vida e de educação (SOUZA, 2007, p. 133).
\end{abstract}

Todavia, as crianças durante os primeiros anos de vida estão no início de seu processo de transformação, recebendo estimulações que favoreça a sua aprendizagem e essas são feitas de acordo com o meio em que ela está inserida. O espaço de educação infantil um de seus meios de convivência, deve ser um ambiente no qual se promove um conjunto de experiências favoráveis à relação das crianças, a socialização e integração entre elas, de saberes artísticos e culturais. Para Kishimoto (2000, p. 12) "O mundo social surge quando a criança interage com outras pessoas para aprender e expressar suas brincadeiras. Pular amarelinha, rodar um pião, jogar peteca:

@rquivo Brasileiro de Educação, Belo Horizonte, v. 6, n. 14, mai-ago, 2018. 
primeiro se aprende e depois se brinca".

Para Silva e Santos (2009), na pesquisa delas,quando a criança escolhe como melhor lugar para brincar ela indica a escola, mostraram que o importante para a criança não é só o brincar, mas sim brincar com o outro, ter a integração, se socializar com os colegas por meio da brincadeira. Brincar só não tem o mesmo valor. Reforça a teoria da necessidade do ser social que se humaniza pelas suas relações e experiências sociais.

\footnotetext{
É curioso notar que as crianças que escolheram a escola como o melhor lugar para brincar, o fizeram porque é na escola onde estão outras crianças. Assim, eles podem trocar experiências com seus colegas e se divertirem em grupo. O brinquedo para as outras crianças é o mais importante, mas para as que escolheram a escola, o outro é o que realmente importa (SILVA; SANTOS, 2009, p. 25).
}

A BNCC apresenta seis direitos de aprendizagem e desenvolvimento na educação infantil. Citamos um deles que é Conhecer-se, que significa construir sua identidade pessoal, social e cultural, constituindo uma imagem positiva de si e de seus grupos de pertencimento, nas diversas experiências de cuidados, interações, brincadeiras e linguagens vivenciadas na instituição escolar e em seu contexto familiar e comunitário.

A busca por equidade na educação demanda currículos diferenciados e adequados a cada sistema, rede e instituição escolar. Por isso, nesse contexto, não cabe à proposição de um currículo nacional (BRASIL, 2017, p. 10). Elaborar ações garantindo o trabalho voltado para o regional e local quanto à cultura, ciência e tecnologia da Amazônia Paraense, requer estudos, pesquisas da parte da coordenação pedagógica e dos professores.

No entanto, há profissionais da educação que, baseados no discurso da "não importância do brincar, 'criança aprende com conteúdo no quadro'", deixam as crianças sem assistência na hora da brincadeira, nos recreios. É importante permitir que as crianças brinquem espontaneamente,

@rquivo Brasileiro de Educação, Belo Horizonte, v. 6, n. 14, mai-ago, 2018. 
pois elas precisam aprender a resolver seus conflitos, no entanto, o mediador deve estar sempre presente para, quando necessário, fazer as interferências.

Para Navarro:

Se o brincar é social, a criança não brinca sozinha, ela tem um brinquedo, um ambiente, uma história, um colega, um professor que media essa relação e que faz do brincar algo criativo e estimulante, ou seja, a forma como o brincar é mediado pelo contexto da escola é importante para que seja de qualidade e realmente ofereça a oportunidade de diferentes aprendizagens para a criança (NAVARRO, 2009, p. 2125).

O brincar é natural na vida das crianças, apenas flui. É algo que faz parte do seu cotidiano e se define como um fazer espontâneo, natural, prazeroso e sem comprometimento, desenvolvida individual ou coletivo. As brincadeiras são universais, estão na história da humanidade ao longo dos tempos, fazem parte da cultura de um país, de um povo.

A brincadeira, segundo Brougère (2001), supõe contexto social e cultural, sendo um processo de relações interindividuais, de cultura. Já Vygotsky (1984) com a teoria conhecida no campo educacional como teoria histórico-social ou histórico-crítica, defende a importância da interação dos sujeitos para o desenvolvimento e aquisição de conhecimentos nas relações. Logo, mediante o ato de brincar, a criança que é sujeito histórico-crítica, explora o mundo e suas possibilidades e se insere nele, de maneira espontânea e divertida, desenvolvendo assim suas capacidades cognitivas, motoras e afetivas.

\section{CIRANDA DA ARTE NA EDUCAÇÃO INFANTIL NA ESCOLA DE APLICAÇÃO}

As DCNEl, em seu Artigo $9^{\circ}$, os eixos estruturantes das práticas pedagógicas dessa etapa da Educação Básica são as interações e as brincadeiras, experiências por meio das quais as crianças podem

@rquivo Brasileiro de Educação, Belo Horizonte, v. 6, n. 14, mai-ago, 2018. 
construir e apropriar-se de conhecimentos por meio de suas ações e interações com seus pares e com os adultos, o que possibilita aprendizagens, desenvolvimento e socialização (BRASIL, 2017, p. 33, Grifo nosso).

A citação em epígrafe de abertura dessa seção de estudo, nos mostra as duas dimensões estruturantes da Educação Infantil as interações e as brincadeiras apresentadas pela BNCC e o porquê da necessidade de tratarmos o tema. O conceito de infância a partir do que foi engendrada para a Educação Infantil pela BNCC, nos mostra a criança como um ser histórico-social. É importante tomarmos ciência desse conceito da criança proposto pela BNCC para compreendermos como se conforma o ensino na Educação Infantil e para entendermos a importância da interação e da brincadeira para o desenvolvimento da criança como ser histórico-social no espaço escolar.

Em consonância com a BNCC as DCNEl/2009 em seu Artigo $9^{\circ}$ define como eixos estruturantes das práticas pedagógicas dessa etapa da Educação Básica as interações e as brincadeiras, devem ser ofertadas experiências em que a criança possa interagir com o "outro" seja criança ou adulto. Pois para Vygotsky (1984), a constituição do ser humano se dá na relação dialética com a sociedade, ele se desenvolve a medida que interage no meio social.

Escravo de jó jogava o cachangá,

Tira, bota, deixa zé Bedelho ficar.

Guerreiros com guerreiros fazem zigue zigue zá

Guerreiros com guerreiros fazem zigue zigue zá

A ciranda com a música "Escravo de Jó5 "faz parte da formação musical de várias gerações de crianças, cantando e sacudindo a latinha ou batendo o sapato no chão para dar o ritmo, girando para a direita ou para

${ }^{5}$ (ESCRAVOS... 2009)

@rquivo Brasileiro de Educação, Belo Horizonte, v. 6, n. 14, mai-ago, 2018. 
a esquerda, devagarzinho ou acelerado, depende do ritmo dado pelo professor. Com essa ciranda quantas habilidades alcançadas nas artes? Coordenação motora, ritmo, lateralidade, percepção auditiva, harmonia sonora, cadência de ritmo, socialização, criatividade, expressar-se.

De acordo com a BNCC, se a criança brinca interagindo com outras crianças, orientada na prática pedagógica pelo professor a partir do campo das experiências: traços, sons, cores e formas, ela pode:

Conviver com diferentes manifestações artísticas, culturais e científicas, locais e universais, no cotidiano da instituição escolar, possibilita às crianças, por meio de experiências diversificadas, vivenciar diversas formas de expressão e linguagens, como as artes visuais (pintura, modelagem, colagem, fotografia etc.), a música, o teatro, a dança e o audiovisual, entre outras (BRASIL, 2017, p. 37).

Desconhecemos outra forma melhor da criança interagir com o outro do que as brincadeiras. Em algumas escolas, na educação infantil a brincadeira não é levada a sério, não é trabalhada como recurso metodológico,mas estudos mostram cada vez mais que o eixo brincar vai ficando mais sério na educação. Dessa forma algumas escolas já adotaram a brincadeira com objetivo de aprendizagem, como nos afirma Andrade (2012, p. 100):

\begin{abstract}
No contexto escolar os jogos são vivenciados pelos alunos, na maioria das vezes, de maneira espontânea, mas a escola quase não tem aproveitado os jogos como recurso metodológico. Porém, já observamos que em alguns espaços educativos existem projetos, ações programadas e atividades de caráter lúdico que são desenvolvidos buscando a melhoria do processo ensinoaprendizagem. (ANDRADE, 2012, p. 100).
\end{abstract}

Verificamos em nossa prática pedagógica que no espaço escolar o lúdico, a brincadeira ainda não é valorizada como um potencial criativo e nem metodológico. A escola não percebe que a brincadeira pode

@rquivo Brasileiro de Educação, Belo Horizonte, v. 6, n. 14, mai-ago, 2018. 
contribuir com as ações para a construção de ideias e saberes elaborados no coletivo; pois as atividades desenvolvidas brincando com objetivos claros, constituem-se, basicamente, em um sistema que integra a vida social da criança, pois ela interage com o "outro" numa prática social, se desenvolvendo como afirma Vygotsky (1984).

Nesse processo, o papel do professor é o de mediador entre o conhecimento sociocultural presente na sociedade e o aprendizado do aluno. "Sendo o processo ensino aprendizagem constituído na interação, o professor está atento e aberto às dúvidas, impasses, curiosidades, formulando sínteses, discutindo significados e ultrapassando limites" (NASPOLINI, 1996, p. 189). Promovendo novos campos de saberes às crianças, que são sem dúvida, ávidas de conhecimentos, experiências e diversas formas de expressão artística e linguagens, como as artes visuais (pintura, modelagem, colagem, fotografia etc.), a música, o teatro, a dança e o audiovisual, entre outras.

Para Barbosa (2011, p. 45) "não há, tampouco, nenhuma razão constrangedora que nos faça duvidar ou negar que as atividades de arte na sala de aula possam promover crescimentos pessoais independente do valor ou da resposta estética". A criança, apenas explora materiais e cria livremente. Para Buoro (2009, p. 33)

\footnotetext{
Ao expressar-se por meio da arte, o aluno manifesta seus desejos, expressa seus sentimentos, expõem enfim sua personalidade. Livre de julgamentos, seu subconsciente encontra espaço para se conhecer, relacionar, crescer dentro de um contexto que o antecede e norteia sua conduta.
}

A criança se expressa naturalmente, tanto do ponto de vista verbal, como plástico, ou corporal com as cantigas de rodas, as cirandas, e sempre motivada pelo desejo da descoberta e por suas fantasias. Ao acompanhar o desenvolvimento expressivo artístico da criança percebe-se que ele resulta 
das elaborações de sensações, sentimentos e percepções vividas intensamente. Porém, as potencialidades estéticas e artísticas infantis não podem se desenvolver isoladas nem de modo unicamente "espontâneo" ou desprovido de intervenções de sua ambiência cultural.

Considerar a expressividade da criança por este ângulo significa entendê-la como um processo de articulação interna e de inter-relação com os outros (como família, professores, seus grupos sociais e culturais). Com efeito, é sempre em contínuo contato com as pessoas e as coisas que a criança aprimora seus pensamentos, suas descobertas e sua expressão artística. Não se trata então de um processo isolado, mas de ações em reciprocidade, quando a criança internaliza os conhecimentos, vinculandoos às suas experiências de vida pessoal e cultural, quer seja, adquiridos na escola ou em outros lugares sociais como a rua, a praça.

Com a BNCC, a expressão artística infantil, é, pois, a mobilização para o exterior de manifestações interiorizadas e que formam um repertório constituído de elementos cognitivos, motores, estéticos e afetivos. Assim, desde bem pequenas em suas experiências artísticas as crianças vão desenvolvendo uma linguagem estética própria, traduzida em signos e símbolos carregados de significação subjetiva e social, como, por exemplo: por meio das brincadeiras de rodas, os jogos simbólicos, as expressões artísticas como pinturas, colagens, as danças folclóricas, das atividades corporais que são extensões de seus gestos primordiais.

Convém lembrar que nas crianças a sensibilidade às cores, formas, sons e movimentos é bem nítida e está sempre presente. Ainda pequenas, demonstram interesses que poderíamos denominar como as primeiras configurações de sentimento estético, cognitivo e motor. Autores como Piaget (1990), Wallon (2001) e Vygotsky (1984), utilizando caminhos diferentes, apresentam-nos suas constatações sobre essas nuances sensíveis e cognitivas. Mostram que as crianças são perfeitamente capazes de 
selecionar formas e objetos que lhes são prazerosos e que mais as atraem, podem ainda, ser introduzidas no processo artístico criativo, porque estão preparadas para praticá-las e compreendê-la.

Entendemos que hoje à luz da BNCC, o maior compromisso do professor na Educação Infantil é trazer para a sua prática pedagógica o campo de experiências: os Traços, sons, cores e formas ao seu trabalho por meio das brincadeiras para que possa desenvolveras percepções artísticas das crianças. Pois assim, com o aprimoramento das potencialidades perceptivas das crianças, pode-se enriquecer suas experiências de conhecimento artístico, social, motor, cognitivo. E isto se dá quando elas são orientadas para observar, ver, ouvir, tocar, sentir, enfim perceber a sua produção artística, as coisas, a natureza e os objetos a sua volta. Sentir, criar, fantasiar, imaginar, representar, faz parte do universo infantil e acompanham o ser humano por toda a vida. Por isso, quando ela desenha, pinta, dança, dramatiza e canta o faz com vivacidade e muita emoção.

Ademais, na Escola de Aplicação da UFPA, a professora em sua prática pedagógica pode promover atividades em que a criança possa se integrar com o outro, se perceber um ser em uma vivência coletiva, em uma prática social, de forma que os diferentes contextos: social, político, econômico e cultural do aluno, sejam respeitados, e a criança possa se desenvolver de forma criativa e expressiva nas artes na Educação Infantil.

\section{O OBSERVADO E DESVELADO NA ESCOLA DE APLICAÇÃO}

No nível de Ensino da educação infantilb da Escola de Aplicação, para atender o propósito de desenvolvimento integral da criança postulado pela BNCC, inclui-se também o desenvolvimento das qualidades humanas (solidariedade, ética, moral, conhecimento de si, respeito ao outro), que

\footnotetext{
${ }^{6}$ Nesse estudo apresentamos fragmentos do texto de PROSCÊNCIO, 2010.
}

@rquivo Brasileiro de Educação, Belo Horizonte, v. 6, n. 14, mai-ago, 2018. 
passa pela dimensão do ser (BRASIL, 2017). Para que o professor desenvolva essas características em suas práticas pedagógicas nas crianças, ele precisa ter construído isso em si durante seu processo formativo.

Vale ressaltar que o observador, em relação ao espaço escolar observado "[...] Seleciona, previamente, qual o seu centro de atenção, ou quais os aspectos a enfocar, a fim de que não se fixe em aspectos menos relevantes em detrimento de outros bem mais importantes para os objetivos da pesquisa" (VIANNA, 2003, p. 89). A preocupação com a observação no lócus da pesquisa é não perder o foco entre tantas informações visuais do campo investigado.

Partindo dessa orientação, metodologicamente nos interessou delimitar a observação na prática pedagógica das professoras da Escola de Aplicação em duas dimensões diferentes, quais sejam: primeiro, nos recreios das crianças, devido a esse momento ser compartilhado com as professoras e estagiários; e segundo,em evento chamado: "Encontro da família na escola", esse por haver apresentações e exposições artísticas das crianças.

A observação no recreio das crianças da Educação Infantil: suscitounos a elucidar que no recreio é o momento da criança brincar livremente, além disso, se desenvolve um dos seis direitos de aprendizagem e desenvolvimento na educação infantil: citamos Expressar-se, a criança se expressa valorizando seu contexto social, ora mostrando o que sabe, ora ainda compartilhando com os colegas mais próximos o que não sabe.

Tal premissa se sustenta na teoria de Vygotsky (1984), que afirma ser necessário considerar dois níveis de desenvolvimento: o real e o potencial. 0 real, é a aprendizagem que já se tornou conhecimento, para as crianças, trata-se das atividades que ela já sabe fazer sozinha, por exemplo: cortar, colar, cantar, desenhar a família. A zona de desenvolvimento potencial se refere ao que a criança ainda não faz sozinha, mas pode fazer com a mediação de outra pessoa (que pode ser adulto ou criança).

@rquivo Brasileiro de Educação, Belo Horizonte, v. 6, n. 14, mai-ago, 2018. 
As duas zonas da teoria de Vygotsky (1984) são trabalhadas durante o recreio, quando a criança (re)afirma o que já sabe e ensina ao colega; e quando esse que ensina tem dúvidas e pergunta à professora sobre alguma situação com relação à cantiga de roda e a expressão artística corporal, ela desenvolve a zona do potencial e a aprendizagem acontece.

Vamos ao campo da experiência: Traços, sons, cores e formas, com base nessas experiências, as crianças se expressam por várias linguagens, criando suas próprias produções artísticas ou culturais, exercitando a autoria (coletiva e individual) com sons, traços, gestos, danças, mímicas, encenações, canções, desenhos, modelagens, manipulação de diversos materiais e de recursos tecnológicos.

Imagem 2 - Criança no Recreio

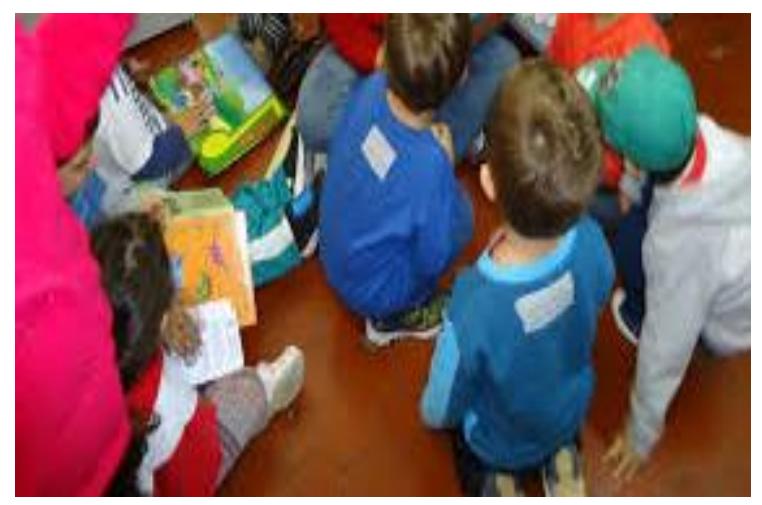

Fonte: Acervo das autoras.

Imagem 3 - Criança Brincando

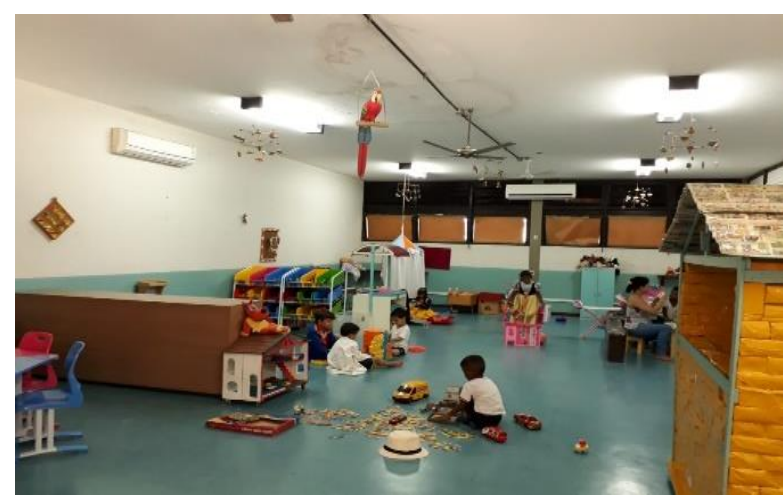

Fonte: Acervo das autoras.

@rquivo Brasileiro de Educação, Belo Horizonte, v. 6, n. 14, mai-ago, 2018. 
Na escola como podemos observar nas imagens 2 e 3, as interações ocorrem o tempo todo entre professor-aluno, aluno-professor, aluno-aluno e com a comunidade escolar. Essa interação social se dá por meio da arte como linguagem. Buoro (2009), considera a concepção de que arte é uma linguagem manifestada desde os primeiros momentos da história do homem e estruturada, em cada época e cultura, de maneira singular, para se expressar social e culturalmente.

Assim, como falamos anteriormente, as artes estão presentes nos momentos festivos da Escola de Aplicação, por meio das linguagens artísticas como a Dança, a Música, as Artes Visuais e o Teatro, os alunos e professores se expressam. Esses festejos são momentos de observação para coleta de dados, a partir da observação, pois, segundo Vianna (2003, p. 89); "A capacidade de observar do ser humano é bastante limitada e o trabalho, certamente, não terá uma conclusão com o êxito esperado se o observador não concentrar sua atenção em determinados aspectos fundamentais para a pesquisa".

Desta forma, firmamos nossa observação sobre o primeiro grande evento da Escola de Aplicação que ocorreu em maio de 2018 no "Encontro da família na escola", esse evento foi escolhido por haver apresentações e exposições artísticas das crianças, o que cumpre a habilidade proposto pela BNCC para o ensino de Música: (EIO3TSO1)7. Utilizar sons produzidos por materiais, objetos e instrumentos musicais durante brincadeiras de faz de conta, encenações, criações musicais, festas e, acrescentamos o coral apresentado pelas crianças que brincando ensaiavam na sala de música, imagem 4, da Educação Infantil, as crianças de forma bem criativa se apresentaram cantando.

\footnotetext{
${ }^{7}$ Codificação conforme estabelecida na Base nacional Comum Curricular.
}

@rquivo Brasileiro de Educação, Belo Horizonte, v. 6, n. 14, mai-ago, 2018. 


\section{Imagem 4 - Sala de música da EAUFPA}

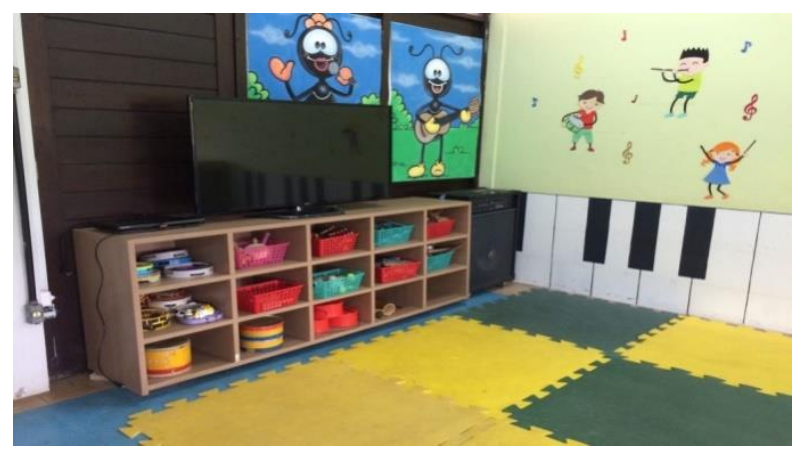

Fonte: Acervo das autoras.

As celebrações na escola são momentos especiais que envolvem todos os níveis de ensino. É o momento de culminância de projetos, apresentações de trabalhos, de expor as produções artísticas dos alunos, conforme a imagem 5 - é a hora de mostrar para além das paredes, fora dos muros escolares revelação da fruição do livre pensamento da criança.

\section{Imagem 5 - Exposição de Trabalhos}

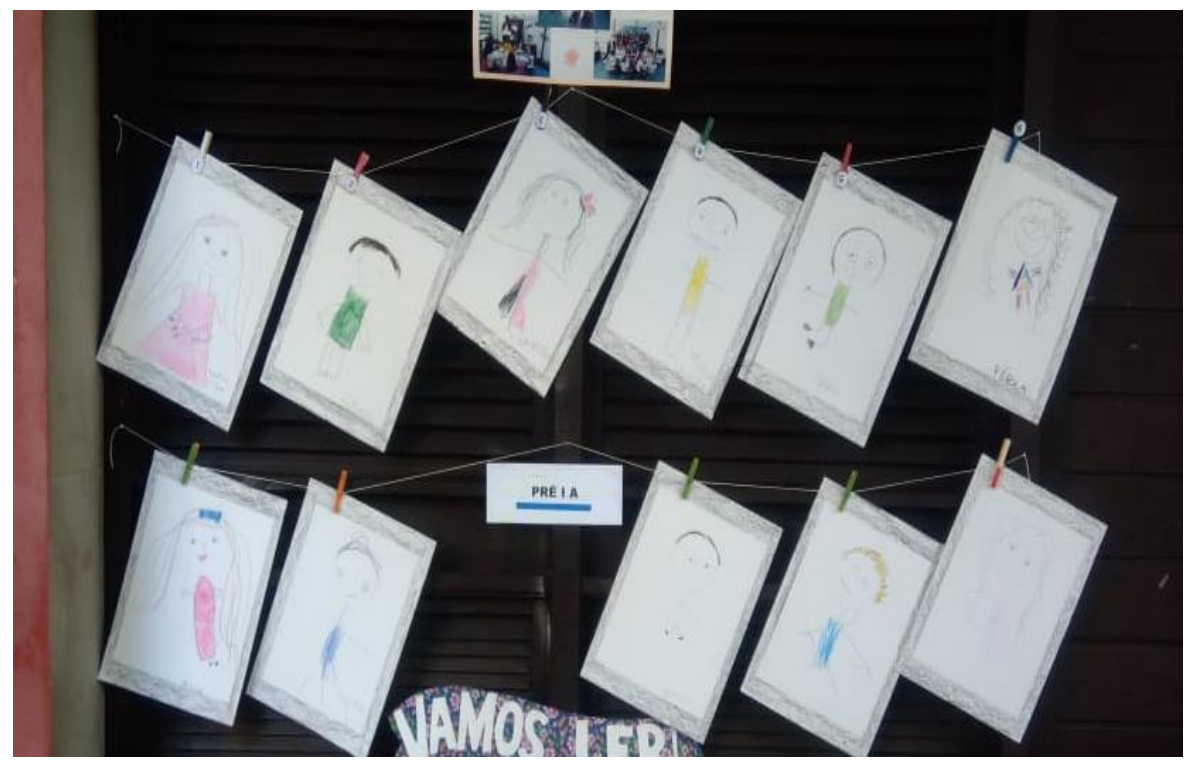

Fonte: Acervo da Escola de Aplicação 


\section{Imagem 6 - Exposição de trabalhos}

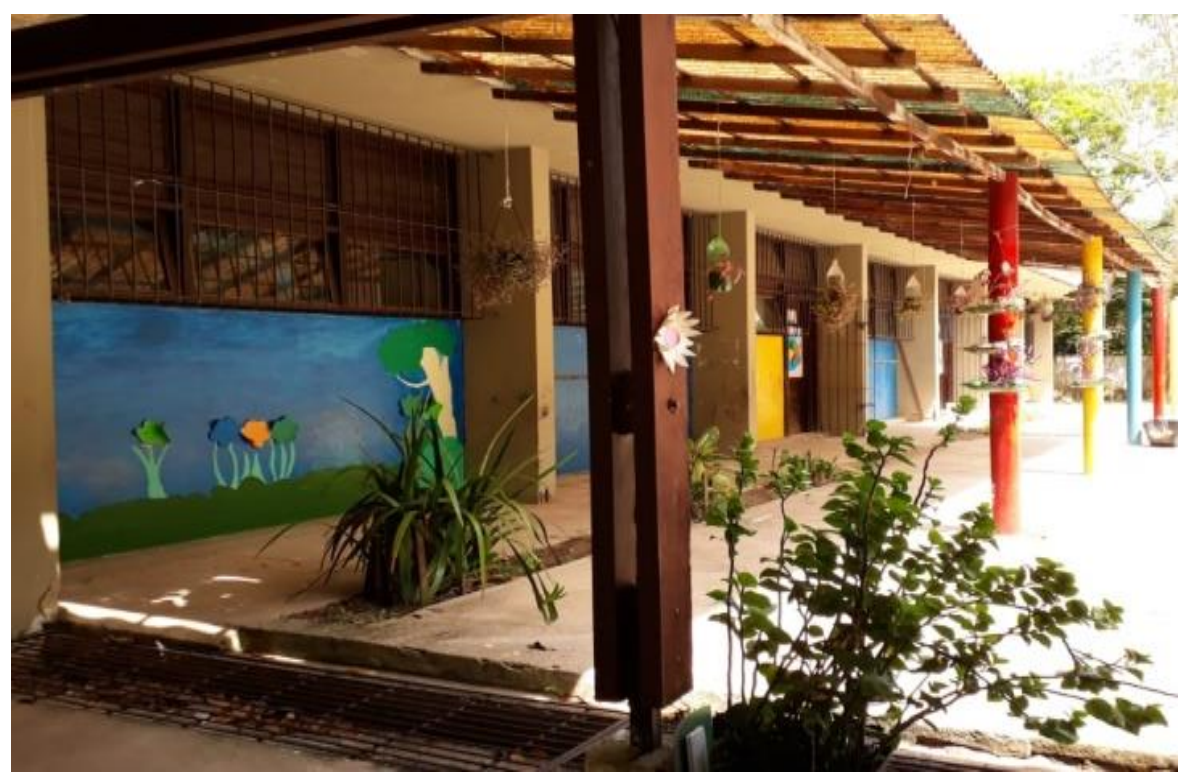

Fonte: Acervo da Escola de Aplicação

Sem perder de vista o campo de experiência indicado pela BNCC, Traços, sons, cores e formas, apresenta como um dos objetivos de aprendizagem e desenvolvimento: (EIO3TS02) ${ }^{8}$. Expressar-se livremente por meio de desenho, pintura, colagem, dobradura e escultura, criando produções bidimensionais e tridimensionais. "Na verdade a criança que pretendemos livre, solta, criativa, só pode existir dentro de uma linguagem criada sobre ela e para ela, e é daí que deve partir o trabalho" (BUORO, 2009, p. 38). É importante planejar a atividade de arte respeitando o nível de maturação da criança da Educação Infantil.

\section{CONSIDERAÇÕES FINAIS}

Este estudo teve como objetivo geral investigar o conceito de infância proposto pela BNCC e a importância do brincar e interagir para o

\footnotetext{
${ }^{8}$ Codificação conforme estabelecida na Base nacional Comum Curricular.
}

@rquivo Brasileiro de Educação, Belo Horizonte, v. 6, n. 14, mai-ago, 2018. 
desenvolvimento artístico da criança na Educação Infantil na Escola de Aplicação da Universidade Federal do Pará (EAUFPA). Entretanto, destacamos que sobre o tema BNCC, Arte e Educação Infantil, o campo é muito vasto, não se esgota aqui, quiçá abre outras possibilidades para pesquisas.

Os resultados mostram por meio deste estudo que a BNCC desvela um conceito de criança histórico-social; na Educação Infantil da Escola de Aplicação, as professoras especialistas de arte promovem as brincadeiras e interação direcionando também para o fazer artístico, contribuindo para o desenvolvimento das habilidades artísticas e criativas da criança, tocando instrumento e cantando, ou no coral, no teatro como personagem, desenhando ou pintando a família, se expressando corporalmente na dança, isso tudo contribui para aprendizagens, desenvolvimento e socialização da criança no meio social.

O fazer artístico acontece com a ciranda das artes, conceito empregado neste estudo que caracteriza-se pela formação de uma grande roda girando ao redor das diversas linguagens artísticas como: as Artes Visuais, a Música, o Teatro e a Dança. Ofertada aos alunos no decorrer do ano por meio das brincadeiras desenvolvidas pelas professoras, geralmente expressadas nas áreas da escola, nos horários do recreio onde as crianças dançam ao som de ritmo lento ou acelerado e repetido das cantigas; se dão justo na relação entre as crianças e às vezes com a inserção dos adultos que também se sentem chamados pela cantiga de roda também chamada de ciranda; outro momento de as crianças mostrarem suas habilidades artísticas são nas datas festivas da EAUFPA.

Assim, a BNCC, apresenta na Educação Infantil cinco campos de experiências, destacamos específico neste estudo o campo de experiência: Traços, sons, cores e formas. Neste campo mostra que, conviver com diferentes manifestações artísticas, culturais e científicas, locais e universais,

@rquivo Brasileiro de Educação, Belo Horizonte, v. 6, n. 14, mai-ago, 2018. 
no cotidiano da instituição escolar, possibilita às crianças desenvolver habilidades artísticas por meio de experiências diversificadas; vivenciar diversas formas de expressão artística e linguagens, como as artes visuais (pintura, modelagem, colagem, fotografia etc.), a música, o teatro, a dança e o audiovisual, entre outras. Mas é preciso que o professor seja o mediador e leve a sério a brincadeira, elencando os objetivos a alcançar.

Ademais, concluímos que na Escola de Aplicação da UFPA, desenvolve-se um trabalho pedagógico ofertando uma ciranda de linguagens artística, o que contribui para $\bigcirc$ desenvolvimento das potencialidades artísticas das crianças, promovendo experiências de conhecimento artístico de Artes Visuais, de Música, de Dança e de Teatro. Parafraseando Barbosa (2011), desenvolvemos a ideia de que a arte tem conteúdo específico a oferecer, algo inerente às artes. Conteúdos estes, que as crianças aprendem por meio da brincadeira, na interação com o outro, por ser um ser histórico-social.

\section{REFERÊNCIAS}

ANDRADE, Simei Santos. (org.). Ludicidade e formação de educadores. Belém: PPGARTES/ICA/UFPA, 2012. (Série Arte e Pensamento).

ARIÈS, Philippe. História social da criança e da família. Tradução de Dora Flaksman. 2. ed. Rio de Janeiro: Zahar Editores, 1981.

BARBOSA, Ana Mae. (org.). Arte-Educação: leitura no subsolo. 8. ed. São Paulo: Cortez, 2011.

BITTENCOURT, Cândida Alayde de Carvalho; SILVA, Anilde Tombolato Tavares da; OLIVEIRA, Marta Regina Furlan de. O Brincar a partir da obra de Pieter Brueghel: um Diálogo entre a Arte e Educação. In:CONGRESSO NACIONAL DA FEDERAÇÃO DE ARTE/EDUCADORES DO BRASIL. 14., 2014, Ponta Grossa. Anais [...]. Ponta Grossa: Universidade Estadual de Ponta Grossa, 2014.

BRASIL. Constituição da República Federativa do Brasil (1988). Brasília, DF: Senado Federal, 1988. 
BRASIL. Lei n 9.394, de 20 de dezembro de 1996. Estabelece as diretrizes e bases da educação nacional. Diário Oficial da União, Brasília, DF, 23 dez. 1996.

BRASIL. Resolução no 5, de 17 de dezembro de 2009. Fixa as Diretrizes Curriculares Nacionais para a Educação Infantil. Diário Oficial da União, Brasília, DF, 18 dez. 2009.

BRASIL. Emenda constitucional n 59, de 11 de novembro de 2009. Diário Oficial da União, Brasília, DF, 12 nov. 2009, Seção 1, p. 8. Disponível em: http://www.planalto.gov.br/ ccivil_03/constituicao/emendas/emc/emc59.htm. Acesso em: 23 mar. 2017

BRASIL. Base Nacional Comum Curricular. Brasília: MEC, 20 de dezembro de 2017. Disponível em: basenacionalcomum.mec.gov.br.Acesso em: 20 dez. 2017.

BUORO, Anamelia Bueno. O olhar em construção: uma experiência de ensino e aprendizagem da arte na escola. 8 ed. - São Paulo: Cortez, 2009.

BROUGÈRE, Gilles. Brinquedo e cultura . 4. ed. São Paulo: Cortez, 2001.

CERVO, Amado Luiz; BERVIAN, Pedro Alcino; SILVA, Roberto da. Metodologia cientifica. 6. ed. São Paulo: Pearson Prentice Hall, 2007.

ESCRAVOS de Jó: musicalização infantil UFPR. YouTube, 29 nov. 2009.

Disponível em: https://www.youtube.com/watch? v=mBjOprq-zOE. Acesso em: 29 out. 2018.

FERRAZ, Maria Heloisa Correia de Toledo; FUSARI, Maria F. de Rezende. Arte na Educação Escolar. São Paulo: Cortez, 2001. (Coleção Magistério $2^{\circ}$ Grau, Série Formação Geral).

FRIEDMANN, Adriana. A arte de brincar: brincadeiras e jogos tradicionais. 3. ed. Petrópolis: Vozes, 2004.

FRANÇA, Rita de Cássia Cabral Rodrigues de;SILVA, Déborah Almeida da; COSTA, Rafaelle Tavares. Ludicidade e prática pedagógica na perspectiva da pedagogia Waldorf: apontamentos preliminares. In:SEMINÁRIO NACIONAL VII REGIONAL SOBRE FORMAÇÃO DE PROFESSORES E RELAÇÕES ÉTNICO-RACIAIS. 5., 2013. Pará Anais [...].Pará, 2013. 
KISHIMOTO, Tizuko M. (org.). Jogo, brinquedo, brincadeira, e a educação. 4. ed. São Paulo: Cortez, 2000.

LAKATOS, Eva Maria; MARCONI, Marina de Andrade. Técnicas de pesquisa: planejamento e execução da pesquisa, amostragens e técnicas de pesquisa, elaboração, análise e interpretação de dados. 6. ed. São Paulo: Atlas, 2006.

LOCKE, John. Ensaio sobre o entendimento humano. Lisboa: Fundação Calouste Gulbecnkian, 1999. v. 1.

MARANHÃO, Diva Nereida Marques Machado. Ensinar brincando: a aprendizagem pode ser uma grande brincadeira. Rio de Janeiro: Wak Editora, 2001.

NASPOLINI, Ana Tereza. Didática do Português - tijolo por tijolo: leitura e produção escrita. São Paulo: Scipione, 1996.

NAVARRO, Mariana Stoeterau. O brincar na educação infantil. In: CONGRESSO NACIONAL DE EDUCAÇÃO/EDUCERE. III ENCONTRO SUL BRASILEIRO DE PSICOPEDAGOGIA, 9., 2009, Paraná. Anais [...]. Parana: PUCPR, 2009. P. 2123-2137.

PIAGET, Jean. A Formação do Símbolo na criança. São Paulo: LTC Editora, 1990.

PROSCÊNCIO, Patrícia Alzira. Concepção de corporeidade de professores da educação infantil e sua ação docente. 2010. 149f. Dissertação (Mestrado) Programa de Pós-Graduação em Educação, Universidade Estadual de Londrina, Londrina, PR, 2010.

SOUZA, Maria Cecília Braz Ribeiro de. A concepção de criança para o Enfoque Histórico Cultural. 2007. Tese (Doutorado em Educação) Faculdade de Filosofia e Ciências, Universidade Estadual Paulista, São Paulo, 2007.

SILVA, Aline Fernandes Felix da; SANTOS, Ellen Costa Machado dos. A importância do brincar na educação infantil. 2009. 36 f. Monografia (Especialização) - Decanto de Pesquisa e Pós- Graduação, Universidade Federal Rural do Rio de Janeiro, Mesquita, 2009. Disponível em: http://www.ufrij.br/graduacao/prodocencia/publicacoes/desafioscotidianos/arquivos/integra/integra_SILVA\%20e\%20SANTOS.pdf. Acesso em: 12 mar. 2019.

@rquivo Brasileiro de Educação, Belo Horizonte, v. 6, n. 14, mai-ago, 2018. 
VIANNA, Heraldo M. Pesquisa em educação: a observação. Brasília: Plano Editora, 2003.

VYGOTSKY, Lev S. A formação social da mente. São Paulo: Martins Fontes, 1984.

WALLON, Henri. Psicologia e Educação de Infância. Rio de Janeiro: Editorial Estampa, 2001.

@rquivo Brasileiro de Educação, Belo Horizonte, v. 6, n. 14, mai-ago, 2018. 